\title{
CONSUMPTION VC THE HEALTH AND ENVIRONMENTAL SHOCKS: THE CASE OF THAILAND
}

\author{
Yuthapoom Thanakijborisut
}

Suan Sunandha Rajabhat University, Bangkok, Thailand

This paper studies consumption insurance against the health and environmental shocks (HES) in Thailand. The paper estimates the impact of household consumption from the change in the health and environmental shocks on total consumption growth and food consumption growth. The HES are measured by the change in health status when at least one of member within the household treated at the service providers as an inpatient. The inpatient is the health care cost of an individual or household's decision in seeking medical care that causes and effects of the household's ability to smooth consumption. This paper uses the data from the Household Social-Economic Panel Survey during 2005 and 2007. The survey collected data on demographic characteristics by the interview from 6,000 households, approximately, from every province, both inside and outside municipal areas in Thailand. The study estimates the change of consumption by using an ordinary least squares (OLS) regression model. The results show that the members within the household changing as inpatient would reduce around 4 percent on total consumption and 6 percent on food consumption, respectively. These results compared to the consumption insurance in the US that consumption drops around 14 percent when at least one household member gets sick. It implies that Thailand has much better consumption insurance. This case indicates that consumption insurance in Thailand is quite sufficient against HES. For the case of Thailand, the well-insured consumption against HES may lead to decrease the spending in public health insurance.

Keywords: consumption insurance, HES, Thailand

\section{Introduction}

In developing countries always encounter with idiosyncratic shocks that impact on the ability of households to smooth consumption. There are apparent shocks in varying natures unpredictably e.g. natural disasters, weather fluctuations, a spell of unemployment and a spell of illness. One of the crucial idiosyncratic shocks is health and environmental shocks (HES). The effect of HES brings households to economic costs in seeking medical care and reducing on consumption. The households could not insure on their consumption during facing the

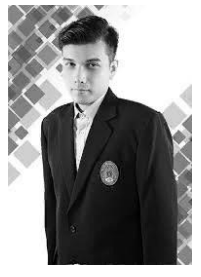

Yuthapoom Thanakijborisut

$\mathrm{PhD}$, lecturer in Faculty of Management Science, Suan Sunandha Rajabhat University, Bangkok, Thailand Research interests: international marketing, customers behavior, behavioral economics, corporative responsibility, business design

Published 5 papers in international journals,

Participated 10 international conferences

Email : yuthapom.th@ssru.ac.th, anovaoad@hotmail.com 


\section{CONSUMPTION VC THE HEALTH}

HES. Particularly, in case of developing countries, formal health insurance does not provide completely for households and individuals.

They rely to use on self-insurance mechanisms largely. Therefore, the health and environmental shocks are the direct costs of a household's decision in seeking medical care that cause and effect of household to smooth consumption. To address this issue, the paper analyzes the consumption insurance against the HES. In particular, the aim of this paper estimates the impact of household consumption from the change in the health and environmental shocks on total consumption growth and food consumption growth. The health and environmental shocks are measured from individual who stayed in a service provider under treatment as inpatient. The representative data used is from the National Statistical Office in the series of the Household Social-Economic Panel Survey (SEPS) during 2005 and 2007 and uses an ordinary least squares (OLS) regression model to find the results. The survey sample includes the demographic and social economic characteristics of nearly 6,000 households for each year households that contain detailed information regarding the characteristics of households from every province in Thailand.

Many studies estimated the impact of household consumption against the health and environmental shocks using different measurements for the HES. Cochrance (1991) tested consumption insurance across individuals by idiosyncratic shock variables such as days of illness, involuntary job loss and weeks spent for looking employment. The estimations were based on the Panel Study of Income Dynamics (PSID) in the USA.

The result of days of illness $\geq 100$ days measured as a dummy variable found that consumption growth decreased around 11 to 14 percent. The estimation results imply that days of illness with long terms were not fully insured. Similarly, there were studies using various methods to measure the variable of HES in other countries. For instance, Gertler and Gruber (2002), Gertler et al. (2009) and Genoni (2012) used the self-reported illness and the physical ability to perform activities of daily living (ADL) index for measuring the change in health in Indonesia. However, they found that illness symptoms were related with increasing consumption but ADL index rejected full consumption insurance. Asfaw and Von Braun (2004) measured the head of the household moves from a healthy to an unhealthy status for the health and environmental shocks to testing purchased food, total food and non-food consumption insurance in rural Ethiopia.

De Weerdt and Dercon (2006) examined the impact of illness shocks on consumption via the role of networks within the village in Tanzania. Wagstaff (2007) studied households in Vietnam which were fully smooth consumption in the face with the HES including death of working age member, any working and non-working member of the household had been hospitalized for seven days or more. Irac and Minoiu (2007) tested smooth consumption in rural household in Romania by run regression with crop disease, animal diseases, illness shocks and etc. Their finding suggests that illness shocks were not fully insured. Considering the HES as chronic illness, Beegle et al. (2008) and Linnemayr (2010) focused on their studies to identify that HIV/AIDS affected household's consumption smoothing. Similarly, 
most of the existing empirical literature focused on consumption insurance; see, e.g., Dercon et al (2005) and Porter (2012). These studies were based on variables of the HES and analyzed aspects of consumption insurance with several shocks. Base on previous studies that the health and environmental shocks was able to reduce on consumption. Thus, the hypothesis of this paper is that the HES would decrease on consumption growth and not fully insured.

According to the data set, this paper uses the conditions of the health and environmental shocks by member within the household treated at the service providers as an inpatient to a proxy for estimations. Although this measurement focuses only the inpatient care, it can show the household faces with more seriously effects than other HES. This shock can cause the more impact on smooth consumption of household.

\section{Model Framework}

This section outlines a simple model of risk sharing as a guideline for the empirical specification employed in this paper. This part is mainly taken from Cochrane (1991), Mace (1991) and Townsend (1994). The major of the risk sharing illustrated that household consumption does not vary in response to idiosyncratic shocks, (here is HES), but varies positively with aggregate consumption. That is households' ability to smooth consumption over time because the risk sharing can moderate idiosyncratic shocks and equalize the marginal utilities across households within a village (or aggregate consumption). Thus, the model studied in this paper links from this literature.

The social planer for determination, the Pereto optimal consumption maximizes the weighted sum of the utility of the $I$ households as following:

$$
\operatorname{Max} \sum_{i=1}^{I} \lambda^{i} \sum_{t=0}^{\infty} \rho_{t}^{i} \sum_{\tau=1}^{s} \pi\left(s_{\tau t}\right) U\left(C_{t}^{i}\left(s_{\tau t}\right), H_{t}^{i}\left(s_{\tau t}\right)\right)
$$

where $\lambda^{i} \in(0,1)$ is the household $i$ 's Pareto weight and $\sum_{i=1}^{I} \lambda^{i}=1 . \rho_{t}^{i}$ is the household $i$ 's rate of time preference. $\pi\left(s_{\tau t}\right) \in[0,1]$ is the probability that state $\left(s_{\tau}\right)$ occurs at time $t$ and $\sum_{\tau=1}^{s} \pi\left(s_{\tau t}\right)=1$ for all $t . C_{t}^{i}\left(s_{\tau t}\right)$ denotes household consumption $i$ in state $\left(s_{\tau}\right)$ at time $t$. $H_{t}^{i}\left(s_{\tau t}\right)$ is a preference of the HES.

subject to the aggregate resource constraint within village and non-negatively conditions are given by

$$
\begin{gathered}
\sum_{i=1}^{I} C_{t}^{i}\left(s_{\tau t}\right) \leq \widehat{C_{t}}\left(s_{\tau t}\right) \\
C_{t}^{i}\left(s_{\tau t}\right) \geq 0
\end{gathered}
$$




\section{CONSUMPTION VC THE HEALTH}

where $\widehat{C_{t}}\left(s_{\tau t}\right)$ is the aggregate consumption available at time $t$ and (3) is the nonnegativity conditions on consumption $C_{t}^{i}$.

For expositional purposes, this study has modeled consumption insurance against the HES by model of risk sharing with a power utility function and multiplicative preference shocks given by

$$
U\left(C_{t}^{i}\left(s_{\tau t}\right), H_{t}^{i}\left(s_{\tau t}\right)\right)=\frac{1}{\sigma}\left(C_{t}^{i}\left(s_{\tau t}\right)\right)^{\sigma} \exp \left(\sigma H_{t}^{i}\left(s_{\tau t}\right)\right)
$$

where $\sigma$ displays the measure of absolute risk aversion, and $\sigma<1$ is required for strictly concave utility.

Consider the household's problem of choosing the consumption as $C_{t}^{i}$ to maximize utility (1) subject to the aggregate resource constraint within village (2) and non-negatively conditions (3) with a corresponding Lagrange multiplier $\left(\mu_{t}\right)$.

$$
\mu_{t}=\frac{\left(\lambda^{i} \exp \sigma H_{t}^{i}\right)^{\frac{1}{1-\sigma}}}{C_{t}^{i}}
$$

Then, taking the logarithm of equation (5) and aggregating over $i$ households.

$$
\log C_{t}^{i}-\log \widehat{C}_{t}=\frac{1}{1-\sigma}\left(\log \lambda^{i}-\hat{\lambda}\right)+\frac{\sigma}{1-\sigma}\left(H_{t}^{i}-\widehat{H}_{t}\right)
$$

Taking the first difference (6) for estimating equation. This model is mainly tested with full consumption insurance. Specifically, the estimation can be written as a linear function as:

$$
\log \left(\frac{C_{t+1}^{i}}{C_{t}^{i}}\right)=\beta_{1} \Delta H_{t+1, t}^{i}+\beta_{2} \log \left(\frac{\widehat{C_{t+1}}}{\widehat{C_{t}}}\right)+\beta_{3} \log \left(\frac{Y_{t+1}^{i}}{Y_{t}^{i}}\right)+\beta_{N} X_{t+1}^{i}+e^{i}
$$

where $C_{t+1}^{i} / C_{t}^{i}$ is the household consumption growth (per capita) of the household $i$ between $t+1$ and $t . \Delta H_{t+1, t}^{i}$ denotes the change in health status of member occurring within the household $i$ between $t+1$ and $t$. In this case, the study measures the change in health status as a dummy variable defined by 1 at least one member within the household treated as inpatient and 0 no member within the household treated as inpatient. If a value of $\beta_{1}$ equals to 0 (full insurance of illness), then there will be fully smooth consumption in the face of the HES. $\widehat{C_{t+1}} / \widehat{C_{t}}$ is the aggregate household consumption growth (per capita) of the village 
between $t+1$ and $t . Y_{t+1}^{i} / Y_{t}^{i}$ is represented by the household income growth (per capita) of the household $i$ between $t+1$ and $t . X_{t+1}^{i}$ is a vector of household characteristics mostly measured at time $t+1$ that includes the control variables for a leader of household $i$ 's characteristics, consisting of gender, age, education, and work.

\section{Data Source}

This study uses the Household Social-Economic Panel Survey (SEPS) conducted by the National Statistical Office (NSO) between 2005 and 2007. The survey collected data of 24,000 individuals or approximately 6,000 households from every province in Thailand. The paper constructs the real household consumption per capita for non-medical care expenditures by grouping expenditures into two categories. First, household total consumption is measured as all expenditure categories and second, household food consumption is measured as expenditure categories on food and drinks for the dependent variables. This paper uses them as the household consumption growth of logarithm for estimation.

Table 1 - Summary statistics of data

(results of the author survey)

\begin{tabular}{|l|c|c|c|}
\hline \multicolumn{1}{|c|}{ Variables } & Mean & S.D. & Number of households \\
\hline Household total consumption in 2007 & $4,012.34$ & $4,017.39$ & 5,962 \\
\hline Household total consumption in 2005 & $3,500.09$ & $3,981.47$ & 5,892 \\
\hline Household food consumption in 2007 & $1,759.14$ & $1,337.54$ & 5,962 \\
\hline Household food consumption in 2005 & $1,640.66$ & $1,214.34$ & 5,892 \\
\hline Health status as inpatient in 2007 & 0.16 & 0.37 & 5,962 \\
\hline Health status as inpatient in 2005 & 0.21 & 0.41 & 5,892 \\
\hline Aggregate total consumption in 2007 & 15.7 & 6.8 & 5,962 \\
\hline Aggregate total consumption in 2005 & 12.7 & 5.6 & 5,962 \\
\hline Aggregate food consumption in 2007 & 7.1 & 2.5 & 5,962 \\
\hline Aggregate food consumption in 2005 & 6.1 & 1.8 & 5,962 \\
\hline Household income in 2007 & $14,032.92$ & $24,795.26$ & 5,962 \\
\hline Household income in 2005 & $16,427.60$ & $59,541.80$ & 5,892 \\
\hline Age of household leader in 2007 & 51.27 & 15.13 & 5,962 \\
\hline Male of household leader in 2007 & 0.67 & 0.47 & 5,962 \\
\hline Education of household leader in 2007 & 0.91 & 0.28 & 5,537 \\
\hline Work of household leader in 2007 & 0.34 & 0.47 & 4,739 \\
\hline
\end{tabular}

Note: total and food consumption, household income in units of baht.

Aggregate total and food consumption in unit of million baht. 


\section{CONSUMPTION VC THE HEALTH}

Considering the health and environmental shocks, this study measures the change in health status when at least one of member within the household treated at the service providers as an inpatient during the twelve months preceding the interview.

For analysis, the health status is a dummy variable that defined by 1 at least one of the members within the household treated as inpatient and 0 no one of the members within the household treated as inpatient. In this study expects that the coefficient of the change in health status variable decreases on household consumption. In addition, the analysis includes control economic independent variables:

Aggregate consumption is represented by regionally aggregate consumption of nation to expressed as growth rate during two periods.

Household income per capita, it is expected that household consumption increases with higher income. For the household characteristics, this study uses the leader of the household that might be correlated with consumption as following:

Age is the age of household leader. The gender of household leader is also included and represented by 1 dummy for male.

Education is represented by the leader's education level, divided into two groups; if 1 for less than a bachelor's degree and 0 for a bachelor's degree or higher.

Finally, the leader's work is reflected by a dummy measure equal to 1 who performs in agricultural sector. The list of all variables is used for estimates in an ordinary least squares (OLS) regression.

\section{Empirical Results}

Table II presents the estimated main results of total and food consumption against health and environmental shocks as inpatient. The estimated effect of the change in health and environmental shocks on household total consumption growth is statistically significant and the coefficient is -0.04 while food household consumption growth is statistically significant and the coefficient is -0.06 .

These results imply that the household reduces consumption when at least one of the members within the household changing as inpatient. For example, the results imply that the members within the household changing as inpatient would reduce around 4 percent on total consumption growth and 6 percent on food consumption growth, respectively. On the considering of the $t$-test, the tests of full insurance implications of $\beta_{1}=0$ are rejected for household total consumption growth and food consumption growth. Overall, these suggest that the effects on household consumption against the health and environmental shocks are not fully insured in case of Thailand. 
Table 2 - The estimated coefficients of consumption insurance against the HES (results of the author survey)

\begin{tabular}{|l|c|c|}
\hline Variables & $\begin{array}{c}\text { Log household total } \\
\text { consumption growth }\end{array}$ & $\begin{array}{c}\text { Log household food } \\
\text { consumption growth }\end{array}$ \\
\hline Change in health status as inpatient & $-0.0410^{* *}$ & $-0.0617^{* * *}$ \\
\hline Log aggregate total consumption growth & $0.3950^{* * *}$ & $(0.0212)$ \\
\hline & $(0.1280)$ & - \\
\hline Log aggregate food consumption growth & - & $0.9090^{* * *}$ \\
\hline & & $(0.1380)$ \\
\hline Log household income growth & $0.1530^{* * *}$ & $0.0907 * * *$ \\
\hline & $(0.0093)$ & $(0.0113)$ \\
\hline Age of household leader & $-0.0035^{* * *}$ & $-0.0016^{*}$ \\
\hline & $(0.0007)$ & $(0.0009)$ \\
\hline Male of household leader & -0.0178 & -0.0155 \\
\hline & $(0.0201)$ & $(0.0244)$ \\
\hline Education of household leader & 0.0297 & 0.0374 \\
\hline & $(0.0308)$ & $(0.0375)$ \\
\hline Work of household leader & -0.0204 & 0.0399 \\
\hline & $(0.0195)$ & $(0.0247)$ \\
\hline Constant & $0.2350^{* * *}$ & -0.0180 \\
\hline & $(0.0528)$ & $(0.0600)$ \\
\hline Observations & 4,438 & 4,398 \\
\hline R-squared & 0.073 & 0.031 \\
\hline
\end{tabular}

Standard errors in parentheses, $* * * \mathrm{p}<0.01, * * \mathrm{p}<0.05, * \mathrm{p}<0.1$

In addition, aggregate total and food consumption growth are positive and statistically significant. Household income growth is positive and statistically significant. The coefficient implies that a $1 \%$ increase in household income growth would raise $0.15 \%$ on total consumption growth and $0.09 \%$ on food consumption growth. The age and gender (male) negatively affect on total and food household consumption growth while education (less than a bachelor's degree) positively affect on both consumption. Finally, the coefficients of work indicate that leader who works in agricultural sector would decrease on household total consumption growth but increase on household food consumption growth.

Table III presents the alternative analysis to estimate the impact of household consumption against the health and environmental shocks. The results show the coefficients of changing in health status as inpatient and highlight the household demographic variables in explaining variations with consumption insurance. Firstly, consideration of the household income is separated into 2 groups from mean of summary statistics of data; (household 


\section{CONSUMPTION VC THE HEALTH}

income less than 14,000 $\mathrm{baht}^{1}$ and higher). The results show that the lower household income has more decrease to change in the HES on household total and food consumption growth than the higher household income.

This could be explained by the fact that the higher household income can easily decide to spend on commodities and services and expect to seek for living much more than one on the lower household income since facing the HES.

Alternatively, the lower household income groups spend less on consumption simply because they do not have as many resources as higher income household groups. Secondly, the gender of household leader, men are less responsive to change in the HES on total and food consumption growth than women. It implies that women as household leader prefer to reduce all consumption for saving their households more often than men as household leader.

Thirdly, the education of leader who studies less than bachelor is high responsive in the health and environmental shocks on both consumption growth. The findings are consistent with the results of gender of household leader as women. Next, in case of household leader who does not work in agricultural sector has a higher drop on total and food consumption since facing the health and environmental shocks.

Table 3 - The estimated coefficients of the HES by household income, gender, education, work and area

\begin{tabular}{|c|c|c|c|c|c|c|c|c|c|c|}
\hline & \multicolumn{2}{|c|}{$\begin{array}{c}\text { Household } \\
\text { income }\end{array}$} & \multicolumn{2}{|c|}{$\begin{array}{c}\text { Gender of } \\
\text { leader }\end{array}$} & \multicolumn{2}{|c|}{$\begin{array}{c}\text { Education of } \\
\text { leader }\end{array}$} & \multicolumn{2}{|c|}{$\begin{array}{c}\text { Work of } \\
\text { leader }\end{array}$} & \multicolumn{2}{|c|}{$\begin{array}{c}\text { Household } \\
\text { area }\end{array}$} \\
\hline Var & $<14,000$ & $>=14,000$ & Male & Female & $<$ bachelor & $\begin{array}{c}>= \\
\text { bachelor }\end{array}$ & $\begin{array}{c}\text { Agri- } \\
\text { culture }\end{array}$ & $\begin{array}{l}\text { No Agri - } \\
\text { culture }\end{array}$ & Urban & Rural \\
\hline \multicolumn{11}{|c|}{ Log household total consumption growth } \\
\hline \multirow[t]{2}{*}{$\Delta H$} & $-0.049 * *$ & -0.019 & -0.027 & $-0.080^{* * *}$ & $-0.041 * *$ & -0.015 & 0.006 & $-0.066 * * * *$ & $-0.067^{* * *}$ & -0.029 \\
\hline & $(0.019)$ & $(0.037)$ & $(0.020)$ & $(0.035)$ & $(0.018)$ & $(0.057)$ & $(0.031)$ & $(0.021)$ & $(0.029)$ & $(0.022)$ \\
\hline Obs & 3,206 & 1,232 & 3,288 & 1,150 & 4,014 & 424 & 1,510 & 2,928 & 1,592 & 2,846 \\
\hline $\mathrm{R}^{2}$ & 0.083 & 0.051 & 0.076 & 0.069 & 0.070 & 0.147 & 0.030 & 0.123 & 0.146 & 0.053 \\
\hline \multicolumn{11}{|c|}{ Log household food consumption growth } \\
\hline \multirow[t]{2}{*}{$\Delta H$} & $-0.065 * * *$ & -0.055 & $-0.052 * *$ & $-0.089 * *$ & $-0.063 * * *$ & -0.045 & -0.038 & $-0.075 * * *$ & $-0.102 * * *$ & -0.042 \\
\hline & $(0.025)$ & $(0.043)$ & $(0.025)$ & $(0.038)$ & $(0.022)$ & $(0.068)$ & $(0.039)$ & $(0.025)$ & $(0.034)$ & $(0.027)$ \\
\hline Obs & 3,175 & 1,223 & 3,261 & 1,137 & 3,980 & 418 & 1,501 & 2,897 & 1,578 & 2,820 \\
\hline $\mathrm{R}^{2}$ & 0.029 & 0.009 & 0.020 & 0.034 & 0.023 & 0.038 & 0.015 & 0.036 & 0.045 & 0.018 \\
\hline
\end{tabular}

Standard errors in parentheses, $* * * \mathrm{p}<0.01, * * \mathrm{p}<0.05,{ }^{*} \mathrm{p}<0.1$

However, this infers that agricultural productivity can specially support on food consumption for family members when household leaders work in agricultural sector. Finally, considering the household area, the estimations show that households living in urban areas have a higher decrease to change in the HES on total and food consumption growth than those in rural areas.

${ }^{1}$ Thai Bath (THB) is a national currency of Thailand, 1 USD $=34,6$ THB (July, 2017) 
Specifically, in this case, the coefficient more reduces around 10 percent on food consumption growth. This implies that the households living in urban are related with the cost of living in urban society. In other words, the households living in rural area have feature as relative household which can lend a hand with consumption of commodities and services more often than in urban area according to Thailand social.

\section{Conclusion and Recommendations}

This paper analyzes the consumption insurance against the health and environmental shocks as inpatient. The findings indicate that the effects on household consumption against the HES are not fully insured in case of Thailand. Especially, the results imply that the members within the household changing as inpatient would reduce around 4 percent on total consumption growth and 6 percent on food consumption growth. These results are consistent with the range of consumption insurance against the HES of other studies e.g., Cochrance (1991) in the USA, Gertler and Gruber (2002) in Indonesia, De Weerdt and Dercon (2006) in Tanzania, Wagstaff (2007) in Vietnam. According to the results, the reducing of household consumption is quite less.

This implies that insuring consumption is fine in case of Thailand. Thai households are well insured against the HES as inpatient. That is, households may be able to smooth consumption because they almost rely to use on self-insurance mechanisms by borrowing informal insurance for health among their kinship systems and neighborhoods. Therefore, these findings infer that government may lead to decrease the spending in public health insurance. Increasing in public health insurance may improve on the welfare slightly. However, government should reallocate the more budget of public health insurance to really lower income households where may not be able to provide the payment or co-payment at medical services since facing the health and environmental shocks.

One limitation in this study, the measurement of the HES is only the change in health status when at least one of member within the household treated at the service providers as an inpatient. Alternatively, consumption insurance against the HES can test from the several health and environmental shocks such as death of household leader, death of working age inside household, acute diseases, and days of sickness. These kinds of the health and environmental shocks can be or be not insured to estimate insuring consumption in Thailand.

\section{Acknowledgement}

The author would like to thank Assoc. Prof. Luedech Girdwichai, the president of Suan Sunandha Rajabhat University, Bangkok, Thailand and Asst. Prof. Prateep Wajeetongratana, the Dean of Faculty of Management Sciences for the full support in this research and also would like to especially thank Weerachart Kilenthong and Lalita Chanwongpaisarn from the University of the Thai Chamber of Commerce for guidance and comments. The author is 


\section{CONSUMPTION VC THE HEALTH}

grateful from all those advisers who kindly provide consulting throughout the period of this paper.

\section{References :}

Asfaw, A. \& Von Braun., (2004). Is Consumption Insured against Illness? Evidence on Vulnerability of Households to HES in Rural Ethiopia, Economic Development and Cultural Change, 53, 1. $115-29$.

Beegle, K., De Weerdt, J. \& Dercon, S., (2008). Adult Mortality and Consumption Growth in the Age of HIV/AIDS, Economic Development and Cultural Change, 56, 2. 299-326.

Cochrane, J., (1991). A simple Test of Consumption Insurance, Journal of Political Economy, 99, 5. 957-76.

De Weerdt, J. \& Dercon, S., (2006). Risk-sharing networks and insurance against illness, Journal of Development Economics, 81, 2. 337-56.

Dercon, S., Hoddinott, J. \& Woldehanna, T., (2005). Shocks and Consumption in 15 Ethiopian Villages, Journal of African Economies, 14, 4. 559-585.

Genoni, M E., (2012). HES and Consumption Smoothing: Evidence from Indonesia, Economic Development and Cultural Change, 60, 3. 475-506.

Gertler, P. \& Gruber, J., (2002). Insuring consumption against illness, American Economic Review, 92, 1. 51-70.

Gertler, P., Levine, D.I. \& Moretti, E., (2009). Do microfinance programs help families insure consumption against illness? Health Economics, 18, 257-273.

Irac, D.M., \& Minoiu, C., (2007), Risk insurance in a transition economyistepievidence from rural Romania, Economics of Transition, 15, 1. 153-173.

Linnemayr, S., (2010). Consumption Smoothing and HIV/AIDS: The Case of Two Communities in South Africa, Economic Development and Cultural Change, 58, 3. 475-506.

Mace, B.J., (1991). Full insurance in the presence of aggregate uncertainty, The Journal of Political Economy, 99, 5. 928-956.

Porter, C., (2012). Shocks, Consumption and Income Diversification in Rural Ethiopia, Journal of Development Studies, 48, 9. 1209-1222.

Townsend, R., (1994), Risk and Insurance in Village India, Econometrica, 62, 3. 539-92.

Wagstaff, A., (2007). The economic consequences of HES: Evidence from Vietnam, Journal of Health Economics, 26, 1, 82-100.

Paper submitted

Paper accepted for publishing

Paper published online
21 October 2018

14 December 2018

31 January 2019 